\title{
The Environmental Impact Mitigation Hierarchy as a Hierarchy of Risk
}

Peter Lukey* and Sukie Paras

National Department of Environmental Affairs, South Africa

*Corresponding author: Peter Lukey, National Department of Environmental Affairs, South Africa, Tel: +27 123999249; E-mail: plukey@environment.gov.za

Received Date: November 09, 2017; Accepted Date: December 13, 2017; Published Date: December 30, 2017

Copyright: (C) 2017 Lukey P, et al. This is an open-access article distributed under the terms of the Creative Commons Attribution License, which permits unrestricted use, distribution, and reproduction in any medium, provided the original author and source are credited.

\begin{abstract}
The general acceptance in South Africa of the environmental impact mitigation hierarchy as a hierarchy of desirability has meant that offsetting, the final option in the hierarchy, is regarded, at best, as the least desirable option and often as an undesirable option. Indeed, in all of the published South African government guidelines on biodiversity offsetting, offsetting is referred to as the 'option of last resort'. This paper proposes that considering the environmental impact mitigation hierarchy as a hierarchy of risk may address the apparent current policy ambivalence and may contribute to the more efficient and effective consideration and use of all the options in the hierarchy.
\end{abstract}

Keywords Biodiversity; Offsetting; Mitigation hierarchy; Policy; South Africa

\section{Introduction}

In the paper on making biodiversity offsets work in South Africa A governance perspective, Lukey, Cumming, Paras, Kubiszewski and Lloyd [1] identified the perception of offsetting as a mitigation option of 'last resort' as one of their theory-related barriers to offsetting. Lukey et al. [1] suggest that describing offsetting as the last-resort in the mitigation hierarchy is often considered to mean that it is an 'undesirable', as opposed to 'least desirable', option and that the associated use of the 'last resort' phrase is seen by some as an indication of government's own ambivalence to the offsetting option. Lukey et al. [1] then intimate that the dearth of offsetting requirements in the environmental authorizations that follow the consideration of the mitigation hierarchy may be evidence of this ambivalence as authorities appear to be more comfortable accepting residual impacts than they are in attempting to offset them.

This paper describes the discussions and debates on this issue during a meeting of key members of the South African biodiversity offsetting community of practice and proposes one possible means of addressing the suspected policy ambivalence to offsetting that may be resulting from the general acceptance in South Africa of the environmental impact mitigation hierarchy as a hierarchy of desirability.

\section{Background and Context}

South Africa's Department of Environmental Affairs is developing national policy on environmental offsetting including specific policy on biodiversity offsetting. From 29 to 30 August 2017, the department hosted an "Environmental/Biodiversity Offsetting Policy Alignment Expert Workshop" as part of the policy development process. The 29 workshop participants included 13 members of the department's offsetting forum, 9 participants from other government departments (national, provincial and municipal) and state-owned entities, 5 consultants and environmental assessment practitioners and 2 environmental non-government organization representatives. The concern that policy ambivalence to offsetting may be resulting from the general acceptance of the environmental impact mitigation hierarchy as a hierarchy of desirability was one of the many issues discussed during this two-day workshop.

\section{The environmental impact mitigation hierarchy}

Ekstrom, Bennun \& Mitchell [2] define the mitigation hierarchy as "the sequence of actions to anticipate and avoid impacts on biodiversity and ecosystem services; and where avoidance is not possible, minimize; and, when impacts occur, rehabilitate or restore; and where significant residual impacts remain, offset." They then go on to note that the mitigation hierarchy is not a standard or a goal, but an approach to mitigation planning that can be used in its own right or as an implementation framework for biodiversity and ecosystem services conservation goals [2].

PricewaterhouseCoopers LLP [3] refer to the mitigation hierarchy as "a tool which aims to help manage biodiversity risk, and is commonly applied in Environmental Impact Assessments (EIAs)."

The most recent published national government description of the environmental impact mitigation hierarchy is provided in the Mining and Biodiversity Guideline: Mainstreaming biodiversity into the mining sector [4]. In summary, these guidelines state that impact mitigation requires proactive planning and that this planning is enabled by implementing the following mitigation hierarchy -

- Avoid or prevent: Avoidance or prevention refers to the consideration of options in project location, sitting, scale, layout, technology and phasing to avoid impacts on biodiversity, associated ecosystem services, and people. This is referred to as 'the best option, but it is acknowledged that avoidance or prevention is not always possible.

- Minimize: Minimization refers to the consideration of alternatives in the project location, sitting, scale, layout, technology and phasing that would minimize impacts on biodiversity and ecosystem services.

- Rehabilitate: Rehabilitation refers to the consideration of the rehabilitation of areas where impacts are unavoidable and 
measures are provided to return impacted areas to a near-natural state or an agreed land use.

- Offset: Offsetting refers to the consideration of measures over and above rehabilitation to compensate for the residual negative effects on biodiversity, after every effort has been made to minimize and then rehabilitate impacts.

\section{Mitigation hierarchy or mitigation sequence}

In order to initiate the discussion and debate around the mitigation hierarchy related policy ambivalence concern during the abovereferenced expert workshop, the department proposed that this concern could be addressed if the mitigation options were considered to be a sequence of options rather than a hierarchy of options.

To support this proposal, it was argued that the word 'hierarchy' means a system in which people or things are arranged according to their importance and that this implies value - things at the top of the hierarchy are more important than things at the bottom. It was then suggested that the use of the word 'hierarchy' had directly resulted in the situation where offsetting was considered as the undesirable mitigation option of last resort [5-7].

With this, the department then proposed that the use of the word 'sequence' instead of hierarchy would address this problem as it means a series of related things or events in the order in which they follow each other. It was submitted that the use of the term 'mitigation sequence' would ensure the implementation of the mitigation options in the correct order - things at the top of the sequence must happen before things at the bottom-without implying value-things at the top of the sequence are no more or less important than things at the bottom.

To further support this proposal, the department noted that, as the 'avoid or prevent' option is at the top of the hierarchy, making it the most important and desirable option, some opponents of the environmental impact assessment process may use this as evidence that environmental management is "anti-development" as it is clear that environmentalists consider avoiding or preventing development as their the most important and desirable option. Although it was acknowledged that this would clearly be a propagandist and transparently perverse interpretation of the intention of the mitigation hierarchy, it was also pointed out that such 'false facts' often had popular appeal.

Although the department acknowledged that the term 'mitigation hierarchy' appeared to be in popular use in the literature, they noted that the term 'mitigation sequence' also appeared from time to time. For example, Clare, Krogman, Foote \& Lemphers [8] state that "many jurisdictions in North America use a 'mitigation sequence' to protect wetlands: First, avoid impacts; second, minimize unavoidable impacts; and third, compensate for irreducible impacts through the use of wetland restoration, enhancement, creation, or protection". McKenney \& Kiesecker [9] also refer to 'steps in a sequence' and Ekstrom et al. [2] define the mitigation hierarchy as "the sequence of actions..."

With this, it was suggested that the word sequence appeared to be a far more accurate and potentially less confusing or misleading description of the ordered series of mitigation interventions that must be considered for efficient and effective impact management.

\section{A hierarchy of value, but what value?}

In response to the department's suggestion that the mitigation options should be termed a sequence rather than a hierarchy, although the workshop broadly acknowledged possible mitigation hierarchy related policy ambivalence in respect of offsetting, there was still strong support for the concept of a hierarchy of value. Although not clearly articulated, there was a general sense from the workshop participants that there was a value associated with each mitigation option and that this value informed the delineation of the options. However, it was also broadly acknowledged that 'desirability' may not be the most appropriate or accurate description of the value underpinning the hierarchy.

Although 'effort' was tentatively submitted as a possible value, this was almost immediately discarded by the workshop.

\section{The mitigation hierarchy as a hierarchy of risk}

Following further discussion around the type of value that underpins the mitigation hierarchy, the workshop agreed that the mitigation hierarchy is actually a hierarchy of risk. The mitigation hierarchy is thus considered to be a hierarchy of the risk of mitigation failure with the option at the top of the hierarchy carrying the least risk and the bottom option carrying the highest level of risk. The workshop agreed that: by definition, there was no risk of the failure of environmental impact mitigation associated with avoidance or prevention; there was certainly a risk associated with minimization; there was an even greater level of risk associated with rehabilitation; but the greatest level of risk was associated with offsetting. In this regard, Maron et al. [10] sum up this risk succinctly as "offsets exchange certain losses for uncertain gains".

Furthermore, with South Africa leaning towards the policy position of offsetting resulting in a 'net gain' rather than 'no net loss', the association of the hierarchy with risk potentially become even more appropriate in that, although offsetting may be riskier than the other mitigation options, it also has the potential to provide benefits to biodiversity that the other options cannot.

\section{Conclusions}

The workshop discussion around addressing the concern that the general acceptance of the environmental impact mitigation hierarchy as a hierarchy of desirability may be resulting in policy ambivalence in respect of offsetting moved away from semantics to a better understanding of the real value that underpins the mitigation hierarchy. The formalisation of this new understanding through South Africa's offsetting policy may lead to an improved use of the mitigation hierarchy and the improved effectiveness of the resulting environmental authorizations.

\section{Acknowledgements}

The authors would like to acknowledge the South African national Department of Environmental Affairs for hosting the Environmental/ Biodiversity Offsetting Policy Alignment Expert Workshop from 29 to 30 August 2017 and the active participation of all the workshop attendees. 
Citation: Lukey P, Paras S (2017) The Environmental Impact Mitigation Hierarchy as a Hierarchy of Risk. J Biodivers Biopros Dev 4: 166. doi: 10.4172/2376-0214.1000166

Page 3 of 3

\section{References}

1. Lukey P, Cumming T, Paras S, Kubiszewski I, Lloyd S (2017) Making biodiversity offsets work in South Africa - a governance perspective. Ecosyst. Serv. 27, 281-290.

2. Ekstrom J, Bennun L, Mitchell R (2015) A cross-sector guide for implementing the Mitigation Hierarchy. Cross-Sector Biodiversity Initiative.

3. PricewaterhouseCoopers LLP (2010) Biodiversity offsets and the mitigation hierarchy: a review of current application in the banking sector. Business and Biodiversity Offsets Programme and the UNEP Finance Initiative. Retrieved 11 08, 2017.

4. Department of Environmental Affairs, Department of Mineral Resources, Chamber of Mines, South African Mining and Biodiversity Forum \& South African National Biodiversity Institute (2013) Mining and Biodiversity Guideline: Mainstreaming biodiversity into the mining sector. Pretoria: Department of Environmental Affairs.
5. Department of Environmental Affairs and Development Planning (2007) Provincial Guideline on Biodiversity Offsets. Cape Town: Department of Environmental Affairs and Development Planning.

6. Ezemvelo KZN Wildlife (2009) Norms and Standards for Biodiversity Offsets: KwaZulu-Natal Province, South Africa. Pietermaritzburg: Ezemvelo KZN Wildlife.

7. Ezemvelo KZN Wildlife (2013) Concise Guideline: Biodiversity Offsets in KwaZulu-Natal, Final Draft, February 2013. Pietermaritzburg: Ezemvelo KZN Wildlife.

8. Clare S, Krogman N, Foote L, Lemphers N (2011) Where is the avoidance in wetland law and policy?. Wetlands Ecol Manage 19: 165-182.

9. McKenney BA, Kiesecker JM (2010) Policy Development for Biodiversity Offsets: A Review of Offset Frameworks. Environ Manage, 45: 165-176.

10. Maron M, Hobbs RJ, Moilanen A, Matthews JW, Christie K, et al. (2012) Faustian bargains? Restoration realities in the context of biodiversity offset policies. Biolo Conserv 155: 141-148. 